\title{
Nutritional status and nutrient adequacy against serum prolactin levels in lactating mothers during the COVID-19 pandemic
}

\author{
Giyawati Yulilania Okinarum ${ }^{\mathrm{a}, 1, *}$, Lestariningsih ${ }^{\mathrm{b}, 2}$, Afroh Fauziah $^{\mathrm{c}, 3}$ \\ a,b,c Universitas Respati Yogyakarta, Jln. Raya Tajem KM 1,5 Sleman Yogyakarta, 55282, Indonesia \\ ${ }^{1}$ gitaajib@gmail.com*; ${ }^{2}$ lestaringsih_respati@yahoo.com; ${ }^{3}$ afrohfauziah@gmail.com \\ * corresponding author
}

\section{ARTICLE INFO}

Article history

Received, $18^{\text {th }}$ March 2021

Revised, 22-nd July 2021

Accepted, $1^{\text {-st }}$ August 2021

Keywords

COVID-19

Lactating mothers

Nutritional status

Nutrient adequacy

Serum prolactin levels

\section{ABSTRACT}

The COVID-19 pandemic is creating global disruption, every area of life is touched. One area that has an impact, is breastfeeding, which is caused by nutritional status and nutrient adequacy during the pandemic, this condition affects prolactin release. Prolactin hormone stimulates and initiate of milk secretion. Midwives employed in maternal-child settings play a pivotal role in facilitating and supporting lactating mothers. This study aimed to identify and analyze the nutritional status and nutrient adequacy against serum prolactin levels in lactating mothers during the COVID-19 pandemic. Sixty lactating mothers from Sleman Regency and Yogyakarta city participated in this cross-sectional study. All were between 0-3 postpartum months. A single blood sample was collected from women at 7-9 am. Serum samples were stored at $2-8^{\circ} \mathrm{C}$ before the prolactin assay by using VIDAS ${ }^{\circledR}$. Data analysis using Kruskal Wallis followed by Post-Hoc Mann Whitney. Results found a statistically significant difference in serum prolactin levels between underweight vs normoweight and normoweight vs overweight $(\mathrm{p}<0.05)$, but there was no significant difference in serum prolactin levels between underweight vs overweight $(\mathrm{p}>0.05)$. Significant differences in serum prolactin levels also found in the nutrient adequacy (energy, carbohydrate, protein, and fat) $(\mathrm{p}<0.05)$. Thus, normoweight and adequate macronutrient during breastfeeding in the COVID-19 pandemic situation had better serum prolactin levels than underweight, overweight and inadequate macronutrient.

This is an open access article under the CC-BY-SA license.

\section{Introduction}

Severe Acute Respiratory Syndrome Coronavirus-2 (SARS CoV-2) is a new type of coronavirus that causes COVID-19, which has been declared by WHO as a world pandemic on March 11, 2020 (Who, 2020; WHO, 2020a, 2020b). Coronavirus spreads so quickly, the cases are increasing and spreading between regions, at the end of the day the President of the Republic of Indonesia has declared an emergency response status and established a public health emergency through Presidential Decree No. 11 of 2020 and Government Regulation No. 21 of 2020 concerning LargeScale Social Restrictions in the context of accelerating the handling of COVID-19 (UNICEF, 2010). The large-scale social restrictions policy in a pandemic situation has a significant impact on society and the country's economic conditions because most Indonesians work in the informal sector. This condition greatly affects the decline in people's purchasing power for nutritious food as well as access to fulfillment of healthy food, which makes it very possible for the emergence of nutritional deficiencies in families, including breastfeeding mothers (Fallo et al., 2019; French et al., 2019; Meerman, J., Aphane, 2012). 
Midwives employed in maternal-child settings play a pivotal role in facilitating and supporting breastfeeding mothers (Swerts et al., 2016). Therefore, midwives have a moral responsibility in society as an effort to develop children optimally (Nursalam et al., 2016). The basic capital for the formation of a quality human being starts when the baby is in the womb, followed by giving breast milk (UNICEF, 2012). Breastfeeding is a natural way to provide food and drink early in a baby's life (UNICEF, 2016). Nutritional factors contribute to the highest mortality rate in infants, which is as much as $53 \%$. As many as 1.4 million children under five are deaths in the world per year, which can be prevented by providing breast milk optimally, this is caused by breast milk which is rich in macro and micronutrients that babies need early in life (UNICEF, 2010). The achievement of exclusive breastfeeding in Indonesia is only $54.3 \%$, which is still far from the national target of $80 \%$ (Dinas Kesehatan Provinsi DIY, 2018). In Indonesia, the proportion of mothers who did not breastfeed their babies because the milk did not come out was $65.7 \%$ and in the $0-6$ month age group who were not breastfed for the same reason was $68.3 \%$.

Nutritional and hormonal factors (prolactin and oxytocin) are the main factors that influence breast milk supply (WHO, 2020a). Nutrients are required for milk synthesis and stimulate the hormone's supply involved in the production and milk secretion. The main hormone that plays a role in lactation is the prolactin hormone. Lack of prolactin levels can inhibit the process of lactogenesis, it is evident that milk secretion stops within three to four days after a decrease in prolactin levels. In addition to producing sufficient milk, a woman must prepare for puberty and pregnancy (McManaman \& Neville, 2006; Pillay \& Davis, 2020; Truchet et al., 2017). This is related to the nutritional status of a woman who needs special attention because nutritional status determines the quality breastfeeding process (Haileslassie et al., 2017; Kominiarek \& Rajan, 2016). During the breastfeeding period, the mother's nutritional needs to be considered because mothers have to produce breast milk for their babies and their nutritional needs must also be met especially during the current pandemic.

The nutritional status of lactating mothers reflects the adequacy of nutrition and the mother's health during breastfeeding. The quantity and quality of breast milk from mothers with normal weight or good nutritional status are more optimal than breast milk from mothers with less nutritional status (Ogechi, 2014). Lactating mothers with good nutritional status have sufficient nutritional reserves so that they can produce breast milk smoothly with sufficient nutritional content (Hatsu et al., 2018; Neville, 2011). Research shows that severe underweight mothers will experience a decrease in the quantity and quality of breast milk, also milk may be a key to target for growth promotion among undernourished children (Dewey et al., 2010; Nakamori et al., 2019). Another study found that a maternal diet can both improve maternal macronutrient intake and the nutritional status of breast milk (Tian et al., 2019). Maternal nutritional status is also related to prolactin levels. In case the nutritional status of lactating mothers higher, thus the serum prolactin levels also higher though (Roelfsema et al., 2012). However, several sources show that mothers who are obese (BMI>30) have a lower prolactin hormone so that they are more at risk of experiencing obstacles in the breastfeeding process (Anstey \& Jevitt, 2011; Mok et al., 2008) although it is not certain what factors the cause.

The correlation between nutritional status and nutritional adequacy against serum prolactin levels in lactating mothers needs special attention, especially in the context of implementing the exclusive breastfeeding program. Prolactin plays an important role in the initiation and synthesis of breast milk in the early stages of breastfeeding. Lack of prolactin levels will inhibit the process of lactogenesis and cause breastfeeding to fail in early life. Thus the present study was undertaken to analyze the nutritional status and nutrient adequacy against serum prolactin levels at 0 to 3 mo postpartum and to analyze the nutrition adequacy among lactating mothers by dietary assessment in Indonesia.

\section{Method}

\section{Study participants}

From September until November 2020, a cross-sectional survey was conducted in Sleman Regency and Yogyakarta City, Indonesia. A survey was carried out in sixty lactating mothers aged 0-3 months were identified, the following criteria: 1) currently breastfeeding; 2) free from medical 
disorder and/or medication; and 3) the baby only consume breast milk. Lactating mothers who had a serious disease, medication or the use of galactagogue pharmaceuticals were automatic as exclusion criteria.

\section{Ethical Approval}

The protocol of this study was approved by the Ethical Committee of Universitas Respati Yogyakarta (approval number: 157.3/FIKES/PL/VII/2020). All study participants signed written informed consent, before conducting the study.

\section{Data collection}

General information such as demographic profiles, anthropometric measurements comprising height and weight were collected. Mothers were weighed with light clothes on a scale. Height was measured to the nearest $0.1 \mathrm{~cm}$. Anthropometric measurements were taken by 2 trained assistants. Nutritional status was categorized as underweight $\left(<18.5 \mathrm{~kg} / \mathrm{m}^{2}\right)$, normal $\left(18.5-24.99 \mathrm{~kg} / \mathrm{m}^{2}\right)$, overweight $\left(25-29.9 \mathrm{~kg} / \mathrm{m}^{2}\right)$, and obese $\left(>30 \mathrm{~kg} / \mathrm{m}^{2}\right)$.

Dietary intakes were collected by $24-\mathrm{h}$ recall method for one day. Interviewers were centrally nutritionist trained and certified in data collection according to standardized methods. The level of detail needed to adequately describe the foods eaten in any 24-h recall was specified for the interviewers by using an integrated form so that information was obtained and recorded consistently and thoroughly. Serving size was determined by dimensional pictures developed for the food intake analysis system by the Ministry of Health, Republic of Indonesia. For calculating the nutrients contents of the diet, the nutritive composition table of Indonesian foods and the USDA National Nutrient Database for Standard reference was used. Daily energy, protein, carbohydrate, and fat were compared with dietary reference intake (DRIs) 2019 in Indonesia. For lactating mothers aged 19-29 years old, the daily energy reference intake is $2380 \mathrm{kcal}$; carbohydrate $405 \mathrm{~g}$; protein $75 \mathrm{~g}$; and fat $67.2 \mathrm{~g}$. Meanwhile, for lactating mothers aged $30-49$ years old, their daily reference intake is 2480 kcal of energy; $385 \mathrm{~g}$ of carbohydrates; $80 \mathrm{~g}$ of protein; and $62.2 \mathrm{~g}$ of fat.

A single blood sample was collected about $3 \mathrm{~mL}$ from nursing mothers at 7-9 am, based on diurnal variation because the highest levels of prolactin serum in the night until morning period. The blood samples were placed in mineral-free tubes (Vaculab Plain). Blood collection was performed by registered medical laboratory technologist and registered midwives who were licensed to perform phlebotomy. After collection, serum samples were kept at $4^{\circ} \mathrm{C}$ and transferred to the laboratory for storage at $2-8^{\circ} \mathrm{C}$ before the prolactin assay by using VIDAS ${ }^{\circledast}$ Prolactin (PRL).

\section{Statistical analysis}

The statistical analyses were performed in IBM SPSS for Windows, version 21.0 (IBM). The Kruskal-Wallis test and Mann Whitney test were used as the data analysis because the data were not normally distributed and followed by Post Hoc analysis with Mann Whitney because there were significantly different the result with p-value $<0.05$.

\section{Results and Discussion}

Sixty breastfeeding mothers from 0-3 months were joined in this study, and no participants were included in the drop out criteria. Participant's characteristics can be seen in Table 1. The table shows that most of the lactating mothers were aged 20-35 years, with the latest high school education, housewife work status, monthly household income during the COVID-19 pandemic in the range of IDR 1,500,000-3,000,000, and have seen pay cuts since the pandemic.

Most of the participants had normal nutritional status and none were obese as shown in Table 2. The data were not normally distributed, so the test was carried out using the Kruskal Wallis test to analyze the comparison of serum prolactin levels between nutritional status groups of lactating mothers. Based on the test results, there were differences in serum prolactin levels in participants with underweight, norm weight (normal), and overweight nutritional status ( $\mathrm{p}<0.05)$. Followed by the Post-Hoc Mann Whitney test to know which groups had significant differences. The test results 
are shown in Table 3 that there was a significant difference in serum prolactin levels in lactating mothers with underweight vs norm weight and norm weight vs overweight group $(\mathrm{p}<0.05)$, while for breastfeeding mothers with underweight vs overweight group there is no significant difference $(\mathrm{p}>0.05)$.

Comparison of the adequacy of macronutrient serum prolactin levels is shown in Table 4, that there were significant differences in the variables of energy, carbohydrate, protein, and fat adequacy on serum prolactin levels in lactating mothers $(\mathrm{p}<0.05)$. In each of the macronutrient adequacy variables, it found that lactating mothers with adequate nutritional intake have high average serum prolactin levels compared to those who less adequate on their nutritional intake.

Table 1. Characteristics of Participants

\begin{tabular}{ccc}
\hline Characteristics & & $\mathbf{n}(\mathbf{\%})$ \\
\hline Age & $<20$ & $11(18,3)$ \\
& $20-35$ & $35(58,3)$ \\
Educational level & $>35$ & $14(23,3)$ \\
& Junior high school & $4(6,7)$ \\
Occupational status & Senior high school & $39(65)$ \\
& College & $17(28,3)$ \\
& Employee & $22(36,7)$ \\
Monthly household income during the pandemic $(\mathbf{R p})$ & Housewife & $38(63,3)$ \\
& $<1,500,000$ & $20(33,3)$ \\
Income status & $1,500,000-3,000,000$ & $30(50)$ \\
& $>3,000,000$ & $10(16,7)$ \\
& Work termination & $4(6,7)$ \\
& Payroll deductions & $35(58,3)$ \\
& Irregular income & $11(18,3)$ \\
\end{tabular}

Table 2. Comparison of Serum Prolactin Levels Based on Nutritional Status

\begin{tabular}{cccc} 
Nutritional status & $\boldsymbol{n}$ & Serum Prolactin Levels & $\boldsymbol{p}$ \\
\hline Underweight & $3(5)$ & $42,96 \pm 29,75$ & $0,000^{*}$ \\
Normoweight & $47(78,3)$ & $102,53 \pm 43,49$ & \\
Overweight & $10(16,7)$ & $44,06 \pm 22,04$ & \\
\hline & $*)$ Significant, based on Kruskal Wallis test
\end{tabular}

Table 3. Comparison of Underweight vs Normal Weight vs Overweight

\begin{tabular}{cc}
\hline Nutritional status & $\boldsymbol{p}$ \\
\hline Underweight vs normal weight & $0,017 * *$ \\
Normal weight vs overweight & $0,000^{* *}$ \\
Underweight vs Overweight & 1,000 \\
\hline
\end{tabular}


Table 4. Comparison of Serum Prolactin Levels Based on Nutrient Adequacy

\begin{tabular}{|c|c|c|c|c|}
\hline \multicolumn{2}{|c|}{ Nutrient adequacy } & \multirow{2}{*}{$\frac{n(\%)}{12(20)}$} & \multirow{2}{*}{$\begin{array}{c}\text { Serum Prolactin Levels } \\
\text { Mean } \pm \text { SD } \\
43,64 \pm 22,45\end{array}$} & \multirow{2}{*}{$\frac{p}{0,000^{*}}$} \\
\hline Carbohydrate & Inadequate & & & \\
\hline & Adequate & $48(80)$ & $101,35 \pm 43,94$ & \\
\hline \multirow[t]{2}{*}{ Protein } & Inadequate & $21(35)$ & $50,62 \pm 20,38$ & $0,000 *$ \\
\hline & Adequate & $39(65)$ & $110,90 \pm 43,03$ & \\
\hline \multirow[t]{2}{*}{ Fat } & Inadequate & $15(25)$ & $44,14 \pm 20,62$ & $0,000 *$ \\
\hline & Adequate & $45(75)$ & $105,03 \pm 42,80$ & \\
\hline \multirow[t]{2}{*}{ Energy } & Inadequate & $20(33,3)$ & $52,66 \pm 25,25$ & $0,000 *$ \\
\hline & Adequate & $40(66,7)$ & $108,38 \pm 43,79$ & \\
\hline
\end{tabular}

*) Significant, based on Mann Whitney test

\subsection{Characteristic of lactating mothers during the pandemic}

Current situation of the COVID-19 pandemic has indeed affected many things, especially in terms of the economy, so that not a few people in Indonesia and even in the world whose economic life has experienced significant changes, from cutting wages, irregular income, to termination of employment. There were also participants in this study who experienced this, only $16.7 \%$ had regular income, the rest was affected by COVID-19 in terms of economy. There are changes in daily food consumption for breastfeeding mothers, but not significantly. An analytical survey in Sulawesi, Indonesia found that there was a relationship between staple food consumption and household income in pregnant and lactating women (Reski et al., 2020). A total of $41.6 \%$ of participants in this study were breastfeeding mothers aged $<20$ years and $>35$ years. Mothers with this age are more at risk and have an impact on the nutritional status of the baby because the mother's body is not ready to have sufficient nutritional reserves for the growth of the baby in the uterus and to produce breast milk optimally. As many as $36.7 \%$ of participants in this study were working mothers, three of whom were breastfeeding mothers who had malnutrition status. Working mothers have less time to breastfeed directly than housewives. This will reduce the opportunity for breastfeeding on-demand, so that the fulfillment of the baby's needs is less than optimal. A study states that the milk production of working mothers is less than mothers who do not work (Marliana, 2018; Sari, 2016). This condition is caused by physical and psychological burden factors related to the mother's work (Xuan \& Nhan, 2018).

\subsection{Nutritional status against serum prolactin levels in lactating mothers}

The increase in maternal weight will affect the volume and nutrient content in breast milk, while the increase in tricep fat thickness will affect the increase in the concentration of fat and energy in breast milk. The protein content of breast milk is reflected in the amount of protein present in the maternal bloodstream, especially for non-nitrogen proteins (creatinine, hormonal peptides, and free amino acids - taurine and glutamate origin) (Anatolitou, 2012; Eidelman \& Schanler, 2018). Lactating mothers who have a good immune system have more protective substances in breast milk than lactating mothers with impaired immunity. Therefore, in the current COVID-19 pandemic situation, the nutritional adequacy of lactating mothers must be guaranteed to increase immunity.

Body Mass Index (BMI) and nutrition are biological/clinical factors that affect prolactin secretion (Anstey \& Jevitt, 2011). Prolactin secretion is regulated primarily by the inhibitory action of dopamine in the hypothalamus. Basal prolactin secretion is positively associated with Body Mass Index and serum estradiol concentration (Roelfsema et al., 2012). Differences in BMI indicate different prolactin dynamics. If the BMI is higher, thus serum prolactin levels also are higher though, it has correlated with adipose cells which are one of the sites for prolactin synthesis and secretion. It is following the results of the study which can be seen in Table 2 that there were differences in serum prolactin levels in the underweight, normoweight, and overweight group. Specifically, significant differences were found in the serum prolactin levels of breastfeeding mothers between the underweight vs normoweight nutritional status group and the normoweight vs overweight group $(\mathrm{p}$ $<0.05$ ), but there was no significant difference in serum prolactin levels in the underweight vs 
overweight nutritional status group ( $p>0.05$ ). In this study, the nutritional status of mothers was dominated by normoweight as much as $78.3 \%$ and did not find maternal obesity.

\subsection{Nutrient adequacy against serum prolactin levels in lactating mothers}

Prolactin secretion by the pituitary is inhibited by dopamine through activation of the dopamine D2 receptor (D2R) in lactotrophic cells. In humans with nutritional status obesity appears to have reduced D2R sites in the brain. Hence, prolactin secretion is increased in obese humans. Prolactin secretion is significantly increased in women. Interestingly, prolactin release is mainly related to the size of the visceral fat mass. These data suggest that spontaneous prolactin release is greatly enhanced in obese women in proportion to the size of their visceral fat mass. Since prolactin is inhibited by D2R activation we speculate that the increase in prolactin secretion may be due to reduced D2R availability in the brain (Al-Chalabi et al., 2020; Freeman et al., 2018; Śtelcl \& Vrublovský, 2018).

Another result of this study is there was a significant difference in the adequacy of energy, carbohydrates, protein, fat, and protein on serum prolactin levels $(\mathrm{p}<0.05)$. Participants who have adequate macronutrient adequacy have a high average serum prolactin level compared to participants with inadequate nutritional adequacy, as shown in Table 4 . To produce milk in the first 6 months of the postpartum period, lactating mothers require $330 \mathrm{kcal} /$ day extra energy. Therefore, mothers should consume adequate energy intakes to support lactation needs. Nutrition recommendations advised a total energy intake of 2380-2480 kcal/day in lactating mothers at 0 to 6 months.

Referring to the result above, mothers should consume energy at least $2380 \mathrm{kcal} /$ day during lactation. In Indonesia, the mean daily energy intake of mothers during lactation is lower than intake during pregnancy. Five percent of lactating mothers who include in the underweight group of this research said that their inadequate energy intake since weariness in caring for their babies and the impact of the economic crisis during the pandemic. A qualitative study reported that factors causing low energy consumption among breastfeeding mothers were poor nutritional knowledge and attitude towards energy requirements during lactation, lack of time to cook and eat because of infant care, reduced consumption of milk and supplements, food restriction and taboo, and suboptimal midwife/health personnel's advice (Fikawati et al., 2018).

Eating a healthy diet based on WHO recommendations and balanced nutrition guidelines is an important way to maintain and enhance immunity and health in the long term. Eating healthy means eating a nutritious, balanced, varied diet, including whole grains, nuts, fruits, vegetables, and animal foods. There is no evidence that certain foods or dietary supplements provide protection against COVID-19, but certain micronutrients can contribute to the immune system. Apart from avoiding foods that are high in salt, sugar, and fat, also maintaining a healthy diet, preventing excess weight, and the risk of non-communicable diseases.

A healthy diet consists of a variety of foods from each type of food group to ensure adequate intake of all essential nutrients; fruits and vegetables in sufficient quantity, as a source of essential vitamins and minerals, fiber, and bioactive compounds; oils and fats in sufficient quantities, especially unsaturated fats such as nuts, fish oils, and seeds; salt and sugar in limited quantities; enough water to stay hydrated; and fortified staple and complementary foods. Accordingly, lactating mothers should notice the adequacy of macronutrient intake during nursing their baby since it could be improved their milk supply and serum prolactin levels.

\section{Conclusion}

Prolactin plays an important role in the initiation and synthesis of breast milk in the early stages of breastfeeding. Lack of prolactin levels will inhibit the process of lactogenesis and cause breastfeeding to fail in early life. The study clearly shows the normoweight and adequate macronutrient during breastfeeding in the COVID-19 pandemic situation had better serum prolactin levels than underweight, overweight, and inadequate macronutrient. Thus, lactating mothers should notice their adequacy of macronutrient intake during lactating their baby since it could be improved their milk supply and serum prolactin levels.

Giyawati Yulilania Okinarum et.al (Nutritional status and nutrient adequacy against serum prolactin levels in...) 
Further research is needed with a larger sample size an on several groups of maternal nutritional status, including the obesity group and micronutrient intake such as iron, zinc, and calcium.

\section{Acknowledgment}

We would like to thank the Ministry of Research and Technology/National Research and Innovation Agency, the Republic of Indonesia for the resarch grant.

\section{References}

Al-Chalabi, Bass, \& Salman, A. (2020). Physiology, Prolactin. In StatPearls. Treasure Island (FL): StatPearls Publishing. https://www.ncbi.nlm.nih.gov/books/NBK507829/

Anatolitou, F. (2012). Human milk benefits and breastfeeding. J Pediat Neonat Individual Med, 1(1), $11-18$

Anstey, \& Jevitt. (2011). Maternal obesity and breastfeeding. A review of the evidence and implications for practice.

Dewey, Cohen, Brown, \& Rivera. (2010). Effects of exclusive breastfeeding for four versus six months on maternal nutritional status and infant motor development: results of two randomized trials in Honduras.

Dinas Kesehatan Provinsi DIY. (2018). Profil Kesehatan DIY 2017.

Eidelman, \& Schanler. (2018). Breastfeeding and the use of human milk.

Fallo, Nuhriwangsa, \& Hanim. (2019). Purchasing power, fruits vegetables consumption, nutrition status among elementary school student. International Journal of Public Health Science (IJPHS), 8(1), 70. https://doi.org/10.11591/ijphs.v8i1.16304

Fikawati, Syafiq, Purbaningrum, \& Karima. (2018). Energy Consumption of Lactating Mothers: Current Situation and Problems. In Makara J. Health Res (p. 80).

Freeman, Kanyicska, \& Lerant. (2018). Prolactin: structure, function, and regulation of secretion. Physiol Rev.

French, Tangney, \& Crane. (2019). Nutrition quality of food purchases varies by household income: the SHoPPER study. BMC Public Health, 19(1), 231. https://doi.org/10.1186/s12889-0196546-2

Haileslassie, Mulugeta, \& Girma. (2017). Feeding practices, nutritional status and associated factors of lactating women in Samre Woreda, South Eastern Zone of Tigray, Ethiopia. Journal of Nutrition, 12(2), 28. https://doi.org/10.1186/1475-2891-12-28

Hatsu, McDougald, \& Anderson. (2018). Effect of infant feeding on maternal body composition. Int Breastfeed J, 3(18). https://doi.org/10.1186/1746-4358-3-18

Kominiarek, \& Rajan. (2016). Nutrition Recommendations in Pregnancy and Lactation. Med Clin North Am, 6(10), 1199-1215. https://doi.org/10.1016/j.mcna.2016.06.004

Marliana, Y. (2018). The Effect of Exclusive Breastfeeding on Baby Growth at Kakait Village, Gunung Sari Sub-District. Jurnal Kesehatan Prima, 11(1), 50. https://doi.org/10.32807/jkp.v11i1.82

McManaman, \& Neville. (2006). Mammary physiology and milk secretion. In Advanced Drug Delivery Reviews (pp. 629-641). 
Meerman, J., Aphane, J. (2012). Impact of high food prices on nutrition. Proceedings for FAO's Expert Consultation on Policy Responses to High and Volatile Food Prices.

Mok, Multon, Piguel, \& Barroso. (2008). Decreased full breastfeeding, altered practices, perceptions, and infant weight change of prepregnant obese women: a need for extra support.

Nakamori, Ninh, Isomura, \& Yoshiike. (2019). Nutritional Status of Lactating Mothers and Their Breast Milk Concentration of Iron, Zinc and Copper in Rural Vietnam. Journal of Nutritional Science and Vitaminology, 55(1), 338-345. https://doi.org/10.3177/jnsv.55.338

Neville. (2011). Anatomy and Physiology of Lactation. Pediatric Clinics of North America. https://doi.org/10.1016/S0031-3955(05)70283-2

Nursalam, Hargono, Susilaningrum, Rachmat, \& Utami. (2016). Midwives Performance in Early Detection of Growth and Development Irregularities of Children Based on Task Commitment. International Journal of Evaluation and Research in Education (IJERE), 5(1), 300. https://doi.org/10.11591/ijere.v5i4.5957

Ogechi, U. P. (2014). A Study of the Nutritional Status and Dietary Intake of Lactating Women in Umuahia, Nigeria. American Journal of Health Research, 2(1), 20-26. https://doi.org/10.11648/j.ajhr.20140201.14

Pillay, \& Davis. (2020). Physiology, Lactation. [Updated 2020 Jul 26]. In: StatPearls [Internet]. Treasure Island (FL): StatPearls https://www.ncbi.nlm.nih.gov/books/NBK499981

Reski, Pebriani, Azizah, Basri, \& Hadju. (2020). Food consumption and household income of pregnant and lactating women. Enfermería Clínica, 30(4), 48-51. https://doi.org/10.1016/j.enfcli.2019.10.038

Roelfsema, Pijl, Keenan, \& Veldhuis. (2012). Prolactin secretion in healthy adults is determined by gender, age and body mass index. In PLoS One, 7(2), (p. e31305). https://doi.org/10.1371/journal.pone.0031305

Sari. (2016). Lack of exclusive breastfeeding among working mothers in Indonesia. Kesmas: National Public Health Journal, 11(2), 61-68. https://doi.org/10.21109/kesmas.v11i2.767

Štelcl, \& Vrublovský. (2018). Prolactin and alteration of fertility. Ceska Gynekol, 83(3), 232-235.

Swerts, Marlie, Westhof, Bogaerts, \& Lemiengr. (2016). Supporting breast-feeding women from the perspective of the midwife: A systematic review of the literature. http://doi.org/10.1016/j.midw.2016.02.016.

Tian, Wu, Lin, \& Chen. (2019). Dietary patterns affect maternal macronutrient intake levels and the fatty acid profile of breast milk in lactating Chinese mothers. J Nutr, 58(1), 83-88. https://doi.org/10.1016/j.nut.2018.06.009

Truchet, Sandrine, \& Honvo-Houeto, E. (2017). Physiology of Milk Secretion. Best Practice \& Research Clinical Endocrinology \& Metabolism. 31(4). https:/doi.org/10.1016/j.beem.2017.10.008

UNICEF. (2010). Improving Exclusive Breast Feeding Practices by using Communication for Development in Infant and young Child Feeding Programs.

UNICEF. (2012). Programming guide: infant and young child feeding. Retrieved from. https://www.unicef.org/nutrition/files/Final_IYCF_programming_guide_June_2012.pdf

UNICEF. (2016). From the first hour of life: Making the case for improved infant and young child feeding everywhere. https://apps.who.int/iris/bitstream/handle/10665/43593/9789241594974_eng_slides.pdf?seque nce $=3 \&$ isAllowed $=\mathrm{y}$ 
Who. (2020). Timeline of WHO's response to the pandemic from 31 December 2019. https://www.who.int/emergencies/diseases/novel-coronavirus-2019/interactive-timeline

WHO. (2020a). Novel corona virus 2019. https://www.who.int/emergencies/diseases/novelcoronavirus-2019

WHO. (2020b). WHO Director-General's remaks at the media briefing on 2019-nCoV on 11 February 2020. https://www.who.int/director-general/speeches/detail/who-director-general-sremarks-at-the-media-briefing-on-2019-ncov-on-11-february-2020

Xuan, \& Nhan. (2018). Breastfeeding experiences of working mothers in Vietnam. Belitung Nursing Journal, 4(1), 279-286. 